\title{
Relative tolerance of different species of Brassica to cadmium toxicity: Coordinated role of antioxidant defense and glyoxalase systems
}

\author{
Jubayer Al Mahmud ${ }^{1,2}$, Mirza Hasanuzzaman ${ }^{3 *}$, Kamrun Nahar ${ }^{1,4}$, Anisur Rahman ${ }^{1,3}$, Masayuki \\ Fujita $^{1^{*}}$
}

${ }^{1}$ Laboratory of Plant Stress Responses, Department of Applied Biological Science, Faculty of Agriculture, Kagawa University, Miki-cho, Kita-gun, Kagawa 761-0795, Japan

${ }^{2}$ Department of Agroforestry and Environmental Science, Faculty of Agriculture, Sher-e-Bangla Agricultural University, Sher-e-Bangla Nagar, Dhaka 1207, Bangladesh

${ }^{3}$ Department of Agronomy, Faculty of Agriculture, Sher-e-Bangla Agricultural University, Sher-e-Bangla Nagar, Dhaka 1207, Bangladesh

${ }^{4}$ Department of Agricultural Botany, Faculty of Agriculture, Sher-e-Bangla Agricultural University, Sher-eBangla Nagar, Dhaka 1207, Bangladesh *Corresponding author: Mirza Hasanuzzaman, e-mail: mhzsauag@yahoo.com; Masayuki Fujita:
fujita@ag.kagawa-u.ac.jp

\begin{abstract}
The present study was carried out to examine the metal accumulation and tolerance abilities of three Brassica species (B. napus, B. campestris, and B. juncea) seedlings exposed to two levels of cadmium (Cd) stress $\left(0.25\right.$ and $0.5 \mathrm{mM} \mathrm{CdCl}_{2}$ for three days). Of the Brassica species studied, B. juncea accumulated the highest amount of $\mathrm{Cd}$ in a dose-dependent manner, and in every case, the $\mathrm{Cd}$ content was higher in the roots than the shoots. Cadmium stress reduced seedlings biomass, leaf relative water content (RWC), and chlorophyll (chl) content, whereas proline (Pro), MDA, and $\mathrm{H}_{2} \mathrm{O}_{2}$ content and lipoxygenase (LOX) activity increased in all species. Under Cd stress, ascorbate (AsA) content reduction was lower and glutathione (GSH) content increase was higher in B. juncea compared with other species. Monodehydroascorbate reductase (MDHAR), glutathione reductase (GR), and superoxide dismutase (SOD) activities increased significantly in B. juncea under Cd stress compared with the other species. Catalase (CAT) activity did not decrease in $B$. juncea due to Cd stress, compared with the other species. Dehydroascorbate reductase (DHAR) activity decreased with both levels of $\mathrm{Cd}$ stress in all species except for $B$. juncea under $0.25 \mathrm{mM} \mathrm{CdCl} 2$ stress. Glyoxalase system components performed better in $B$. juncea than the other species under Cd stress. Methylglyoxal (MG) increased substantially under both levels of Cd stress, but MG content was lower in $B$. juncea compared with the others. Considering the antioxidant defense and glyoxalase systems performance $B$. juncea is relatively tolerant species to $\mathrm{Cd}$ toxicity though it accumulated highest $\mathrm{Cd}$.
\end{abstract}

Key words: Abiotic stress; Heavy metal; Methylglyoxal; Phytoremediation; Reactive oxygen species.

Abbreviations: AO_Ascorbate oxidase, APX_Ascorbate peroxidase, AsA_Ascorbic acid, CAT_Catalase, CDNB_1-Chloro-2,4dinitrobenzene, DAB_Diaminobenzidine, DHA_Dehydroascorbic acid, DHAR_Dehydroascorbate reductase, DTNB_5,5-Dithio-bis(2-nitrobenzoic) acid, EDTA_Ethylenediaminetetraacetic acid, Gly_Glyoxalase, GR_Glutathione reductase, GSH_Reduced glutathione, GSSG_Oxidized glutathione, GPX_Glutathione peroxidase, GST_glutathione $S$-transferase, LOX_Lipoxygenase, MDHAR_Monodehydroascorbate reductase, MG_Methylglyoxal, NBT_Nitroblue tetrazolium chloride, NTB_2-Nitro-5-thiobenzoic acid, Pro_Proline, ROS_Reactive oxygen species, SLG_S-D-lactoyl-glutathione, SOD_Superoxide dismutase, TBA_Thiobarbituric acid, TCA_Trichloroacetic acid

\section{Introduction}

Fast industrialization due to rapid increase of population causes serious environmental problems including the production and release of different toxic metals into the environment (Hasanuzzaman et al., 2013). Among the toxic metals cadmium $(\mathrm{Cd})$ has assumed important environmental contaminant in terms of damage to plant growth and human health (Heyes, 1997; Nouairi et al., 2009; Hasanuzzaman et al., 2013). Plants grown in $\mathrm{Cd}$ rich soil show different abnormalities like chlorosis, necrosis, leaf rolling, root growth inhibition and stunted plant growth. Cd also altered stomatal action, decreased water potential, cation efflux, alterations in membrane functions, photosynthesis inhibition, altered metabolism, altered activities of several key enzymes, and even death (Sharma and Dubey, 2007; Dubey, 2011; Gill et al., 2011; Hasanuzzaman et al., 2013). Normally, Cd stored in the apoplast and the vacuoles of plant cell. Free $\mathrm{Cd}$ ions in the cytosol create toxicity to plant cells and as a non-redox metal, $\mathrm{Cd}$ is unable to generate reactive oxygen species (ROS) directly through Haber-Weiss reactions. Reactive oxygen species overproduction and occurrence of oxidative stress in plants could be the indirect consequence of Cd toxicity. The mechanisms include interacting with the antioxidant system (Srivastava et al., 2004), upsetting the electron transport chain (Qadir et al., 2004), as well as the metabolism of crucial plant nutrients (Dong et al., 2006). Reactive oxygen species (singlet oxygen, ${ }^{1} \mathrm{O}_{2}$; superoxide, $\mathrm{O}_{2}{ }^{-{ }^{-}}$; hydrogen 
peroxide, $\mathrm{H}_{2} \mathrm{O}_{2}$; hydroxyl radical, $\mathrm{OH}^{*}$ ) are able to damage biomolecules including proteins, lipids, and DNA (Hasanuzzaman and Fujita, 2012). Methylglyoxal (MG) is another cytotoxic reactive oxidative compound over produced under abiotic stresses, including metal toxicity (Yadav et al., 2005a; Yadav et al., 2008; Suhartono et al., 2014). Methylglyoxal damages cellular ultra-structural components, and able to damage DNA and cause mutations.

To mitigate the deleterious effect of plants have evolved different mechanisms of defense against $\mathrm{Cd}$ toxicity. Plants can avoid metal toxicity through metal binding to the cell wall, by reducing transport across the cell membrane and by active efflux (Li et al., 2002; Hall, 2002). Plants can also work against $\mathrm{Cd}$ stress through metal chelation, exclusion, active excretion or compartmentalization (Gratão et al., 2005). Moreover, to minimize oxidative stress plant cells are equipped with antioxidant defense system composed of nonenzymatic antioxidants (ascorbic acid, AsA; glutathione, GSH; phenolic compounds; alkaloids; nonprotein amino acids and $\alpha$-tocopherols) and enzymatic antioxidants (superoxide dismutase, SOD; catalase, CAT; ascorbate peroxidase, APX; glutathione reductase, GR; monodehydroascorbate reductase, MDHAR; dehydroascorbate reductase, DHAR; glutathione peroxidase, GPX; and glutathione $S$-transferase, GST) (Pang and Wang, 2008; Gill and Tuteja, 2010; Hasanuzzaman et al., 2012a). Plants also have an MG detoxification system including two vital enzymes, glyoxalase I (Gly I) and glyoxalase II (Gly II), where GSH acts as co-factor. However, the efficiency of this system greatly varies with plant genotypes and environmental stimuli. Plant-based remediation system or phytoremediation is well-known all over the globe, and considered one of the low cost, novel, green technology. To find out suitable plants for $\mathrm{Cd}$ removal from the contaminated soil, a broader understanding is needed of the physiological and biochemical features of potentially useful species. Members of the Brasicaceae family are promising candidates for phytoextraction of heavy metals such as $\mathrm{Cd}, \mathrm{Pb}, \mathrm{Zn}$ and $\mathrm{Ni}$ (Prasad and Freitas, 2003; Robinson et al., 2009), but the degrees of tolerance of different Brassica species are not same in terms of metal accumulation.

So far, only a few articles have been published on the growth and physiological differences among Brassica species. However, the antioxidant defense and glyoxalase system have not been investigated. Therefore, this study was designed to examine the relative tolerance of Brassica campestris, Brassica napus and Brassica juncea against various $\mathrm{Cd}$ concentrations. The antioxidant defense and glyoxalase systems along with $\mathrm{Cd}$ accumulation and level of tolerance and detoxification strategy adopted by the plants were investigated.

\section{Results}

\section{Cadmium accumulation in the shoots and roots}

Three Brassica species accumulated $\mathrm{Cd}$ in their shoots and roots as a result of $\mathrm{Cd}$ exposure, and the accumulation increased with the increase in stress level. Cadmium accumulation was higher in the roots than in the shoots in all three species. Brassica juncea accumulated more $\mathrm{Cd}$ in its shoots and roots than B. campestris and B. napus (Table 1). Under $0.25 \mathrm{mM} \mathrm{CdCl} 2$ stress, the shoots of $B$. juncea accumulated 29 and $27 \%$ higher $\mathrm{Cd}$ than $B$. campestris and $B$. napus, respectively, whereas under $0.5 \mathrm{mM} \mathrm{CdCl}_{2}$ stress, $B$. juncea accumulated 13 and $9 \%$ higher $\mathrm{Cd}$ than $B$. campestris and $B$. napus, respectively. Similarly, under $0.25 \mathrm{mM} \mathrm{CdCl}_{2}$ stress, the roots of $B$. juncea accumulated 65 and $64 \%$ higher $\mathrm{Cd}$ than B. campestris and B. napus, respectively, whereas under $0.5 \mathrm{mM} \mathrm{CdCl}{ }_{2}$ stress, $B$. juncea accumulated 41 and $19 \%$ higher Cd than B. campestris and B. napus, respectively.

\section{Plant growth and biomass production}

Upon exposure to $0.25 \mathrm{mM} \mathrm{CdCl}_{2}$, no significant change in plant height was observed in any of the species tested, while exposure to $0.5 \mathrm{mM} \mathrm{CdCl}_{2}$ resulted significant decreasing of plant height in B. campestris and B. napus but not in $B$. juncea (Table 1). Fresh weight and DW of all three Brassica species decreased under $\mathrm{Cd}$ stress in a dose-dependent manner (Table 1).

\section{Leaf relative water content and proline content}

Leaf RWC of all the Brassica seedlings decreased due to Cd stress with the increase of $\mathrm{CdCl}_{2}$ doses (Table 2). Proline content in all three Brassica species increased substantially with the increase of Cd stress, but the increase in Pro was higher in B. juncea than the other two species (Table 2).

\section{Photosynthetic pigments}

Chlorophyll $a$ and $b$ contents decreased in all three Brassica species with the increase in $\mathrm{CdCl}_{2}$ dosage, but the decrease in chl was lower in B. juncea than the other two species (Table 2).

\section{Oxidative damage}

Cadmium resulted in severe oxidative stress in all three Brassica species (Fig 1). Histochemical staining indicated accumulation of ROS as dark blue spots of $\mathrm{O}_{2}{ }^{--}$and brown spots of $\mathrm{H}_{2} \mathrm{O}_{2}$ in the leaves of plants (Fig 1A, B). MDA content increased significantly in all three species under both levels of Cd stress, and compared with control, the rate of increase was lower in B. juncea (Fig 2A). MDA content increased by 74,57 , and $55 \%$ under $0.25 \mathrm{mM} \mathrm{CdCl}_{2}$, and 114 , 94 , and $85 \%$ under $0.5 \mathrm{mM} \mathrm{CdCl}_{2}$ in B. campestris, B. napus, and $B$. juncea, respectively, compared with the control plants. A similar result was also observed for $\mathrm{H}_{2} \mathrm{O}_{2}$ (Fig 2B). LOX activity markedly increased by 46,85 , and $20 \%$ under 0.25 $\mathrm{mM} \mathrm{Cd}$ stress, and 65,181 , and $39 \%$ under $0.5 \mathrm{mM} \mathrm{Cd}$ stress in $B$. campestris, B. napus, and B. juncea respectively, compared with the control seedlings (Fig 2C).

\section{Ascorbate and glutathione pools}

Both levels of $\mathrm{Cd}$ treatment decreased the AsA content of all three species of Brassica (Fig 3A). However, the rate of reduction of AsA content was higher in $B$. campestris and $B$. napus than $B$. juncea under $0.5 \mathrm{mM} \mathrm{CdCl} \mathrm{Cl}_{2}$. Seedlings of all three species treated with $\mathrm{Cd}$ had significantly increased dehydroascorbate (DHA) content except $B$. campestris under $0.25 \mathrm{mM} \mathrm{Cd}$ (Fig 3B), but in B. juncea, the level of DHA increase was lower than the other two species. The AsA/DHA ratio of all Brassica species decreased under $\mathrm{Cd}$ stress in dose dependant manner (Fig 3C). Cadmium stress significantly increased GSH levels in all three Brassica species, compared with the control seedlings (Fig 3D), and the highest increase was observed in B. juncea. GSSG content also increased in all three species in the same manner as GSH, but the lowest rate of increase was recorded in $B$. juncea (Fig 3E). Compared with control, the GSH/GSSG ratio decreased by 21 and $32 \%$ in B. campestris, and 9 and $31 \%$ 
Table 1. Cd content in shoot and root, plant height, fr wt and dry wt of different Brassica species under Cd stress. $\mathrm{Cd} 1$ and $\mathrm{Cd} 2$ indicate $0.25 \mathrm{mM} \mathrm{CdCl}_{2}$ and $0.5 \mathrm{mM} \mathrm{CdCl}_{2}$, respectively.

\begin{tabular}{|c|c|c|c|c|c|c|}
\hline Treatments & & $\begin{array}{l}\text { Cd content in shoot (mg } \\
\left.\mathrm{g}^{-1} \mathrm{DW}\right)\end{array}$ & $\begin{array}{l}\text { Cd content in root (mg } \\
\left.\mathrm{g}^{-1} \mathrm{DW}\right)\end{array}$ & $\begin{array}{l}\text { Plant height } \\
(\mathrm{cm})\end{array}$ & $\begin{array}{l}\text { Fresh weight } \\
\left(\mathrm{mg} \mathrm{seedling}^{-1}\right)\end{array}$ & $\begin{array}{l}\text { Dry weight } \\
\left(\mathrm{mg} \mathrm{seedling}^{-1}\right)\end{array}$ \\
\hline \multirow[t]{3}{*}{ B. campestris } & Control & $\mathrm{ND}$ & ND & $3.63 \pm 0.18 \mathrm{e}$ & $54.3 \pm 0.9 \mathrm{~d}$ & $5.6 \pm 0.18 \mathrm{~d}$ \\
\hline & $\mathrm{Cd} 1$ & $0.70 \pm 0.03 \mathrm{~d}$ & $6.39 \pm 0.23 \mathrm{e}$ & $3.48 \pm 0.18$ ef & $49.3 \pm 0.6 \mathrm{f}$ & $4.8 \pm 0.04 \mathrm{e}$ \\
\hline & $\mathrm{Cd} 2$ & $1.09 \pm 0.04 \mathrm{~b}$ & $11.26 \pm 0.07 \mathrm{c}$ & $3.37 \pm 0.15 \mathrm{f}$ & $47.3 \pm 0.6 \mathrm{~g}$ & $4.6 \pm 0.04 \mathrm{f}$ \\
\hline \multirow[t]{3}{*}{ B. napus } & Control & ND & ND & $4.77 \pm 0.10 \mathrm{a}$ & $66.4 \pm 1.0 \mathrm{a}$ & $6.5 \pm 0.08 \mathrm{a}$ \\
\hline & $\mathrm{Cd} 1$ & $0.71 \pm 0.07 \mathrm{~d}$ & $6.45 \pm 0.05 \mathrm{e}$ & $4.58 \pm 0.08 \mathrm{ab}$ & $61.8 \pm 1.2 \mathrm{~b}$ & $5.9 \pm 0.04 b$ \\
\hline & $\mathrm{Cd} 2$ & $1.13 \pm 0.01 \mathrm{~b}$ & $13.33 \pm 0.42 b$ & $4.48 \pm 0.08 \mathrm{bc}$ & $59.8 \pm 0.4 \mathrm{c}$ & $5.7 \pm 0.14 \mathrm{c}$ \\
\hline \multirow[t]{3}{*}{ B. juncea } & Control & ND & ND & $4.30 \pm 0.05 \mathrm{~cd}$ & $59.4 \pm 0.7 \mathrm{c}$ & $6.4 \pm 0.06 \mathrm{a}$ \\
\hline & $\mathrm{Cd} 1$ & $0.90 \pm 0.01 \mathrm{c}$ & $10.55 \pm 0.09 \mathrm{~d}$ & $4.23 \pm 0.03 \mathrm{~d}$ & $55.0 \pm 1.3 \mathrm{~d}$ & $5.8 \pm 0.04 \mathrm{bc}$ \\
\hline & $\mathrm{Cd} 2$ & $1.23 \pm 0.01 \mathrm{a}$ & $15.91 \pm 0.01 \mathrm{a}$ & $4.18 \pm 0.03 \mathrm{~d}$ & $52.4 \pm 0.8 \mathrm{e}$ & $5.5 \pm 0.08 \mathrm{~d}$ \\
\hline
\end{tabular}

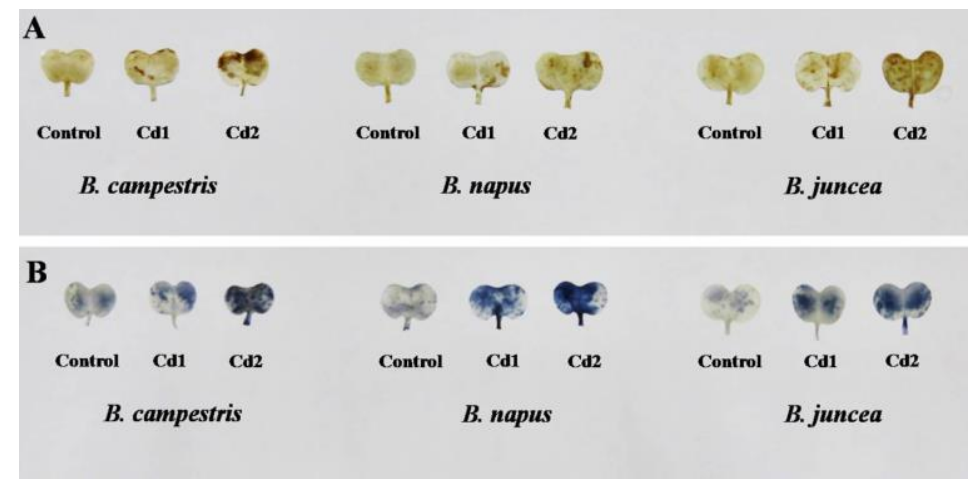

Fig 1. Histochemical detection of $\mathrm{H}_{2} \mathrm{O}_{2}$ (A) and $\mathrm{O}_{2}{ }^{--}$(B) of different Brassica species under Cd stress. Cd1 and Cd2 indicate 0.25 $\mathrm{mM} \mathrm{CdCl}_{2}$ and $0.5 \mathrm{mM} \mathrm{CdCl}_{2}$, respectively.

Table 2. Leaf RWC, Pro content, chl $a$ and chl $b$ content of different Brassica species under Cd stress. Cd1 and Cd2 indicate 0.25 $\mathrm{mM} \mathrm{CdCl}_{2}$ and $0.5 \mathrm{mM} \mathrm{CdCl}_{2}$, respectively

\begin{tabular}{llcccc}
\hline Treatments & Leaf RWC $(\%)$ & $\begin{array}{c}\text { Pro content } \\
\left(\mu \mathrm{mol} \mathrm{g} \mathrm{g}^{-1} \mathrm{FW}\right)\end{array}$ & $\begin{array}{c}\text { chl } a \text { content } \\
\left(\mathrm{mg} \mathrm{g}^{-1} \mathrm{FW}\right)\end{array}$ & $\begin{array}{c}\text { chl } b \text { content } \\
\left(\mathrm{mg} \mathrm{g}^{-1} \mathrm{FW}\right)\end{array}$ \\
\hline B. campestris & Control & $89.43 \pm 0.9 \mathrm{a}$ & $1.23 \pm 0.13 \mathrm{e}$ & $0.97 \pm 0.027 \mathrm{~b}$ & $0.34 \pm 0.009 \mathrm{a}$ \\
& $\mathrm{Cd} 1$ & $87.72 \pm 1.6 \mathrm{bc}$ & $1.71 \pm 0.11 \mathrm{~d}$ & $0.49 \pm 0.004 \mathrm{~g}$ & $0.19 \pm 0.026 \mathrm{c}$ \\
& $\mathrm{Cd} 2$ & $84.92 \pm 1.6 \mathrm{~d}$ & $2.14 \pm 0.05 \mathrm{c}$ & $0.27 \pm 0.014 \mathrm{i}$ & $0.12 \pm 0.009 \mathrm{~d}$ \\
B. napus & Control & $90.99 \pm 0.9 \mathrm{a}$ & $1.20 \pm 0.11 \mathrm{e}$ & $1.03 \pm 0.014 \mathrm{a}$ & $0.34 \pm 0.019 \mathrm{a}$ \\
& Cd1 & $86.87 \pm 0.3 \mathrm{~b}$ & $1.82 \pm 0.14 \mathrm{~d}$ & $0.59 \pm 0.016 \mathrm{e}$ & $0.22 \pm 0.009 \mathrm{~b}$ \\
& Cd2 & $82.54 \pm 1.0 \mathrm{~d}$ & $2.55 \pm 0.05 \mathrm{~b}$ & $0.35 \pm 0.004 \mathrm{~h}$ & $0.14 \pm 0.008 \mathrm{~d}$ \\
& Control & $88.34 \pm 1.6 \mathrm{~b}$ & $1.27 \pm 0.13 \mathrm{e}$ & $0.92 \pm 0.015 \mathrm{c}$ & $0.33 \pm 0.012 \mathrm{a}$ \\
& $\mathrm{Cd} 1$ & $85.21 \pm 1.4 \mathrm{~cd}$ & $2.22 \pm 0.06 \mathrm{c}$ & $0.67 \pm 0.029 \mathrm{~d}$ & $0.23 \pm 0.013 \mathrm{~b}$ \\
& $\mathrm{Cd} 2$ & $83.97 \pm 1.5 \mathrm{~d}$ & $3.09 \pm 0.04 \mathrm{a}$ & $0.53 \pm 0.019 \mathrm{f}$ & $0.19 \pm 0.011 \mathrm{c}$ \\
\hline
\end{tabular}

Means ( \pm SD) were calculated from three replic ations for each treatment. Values with different letters are significantly diffe rent at $\mathrm{P} \leq 0.05$ applying the Fisher's LSD test.
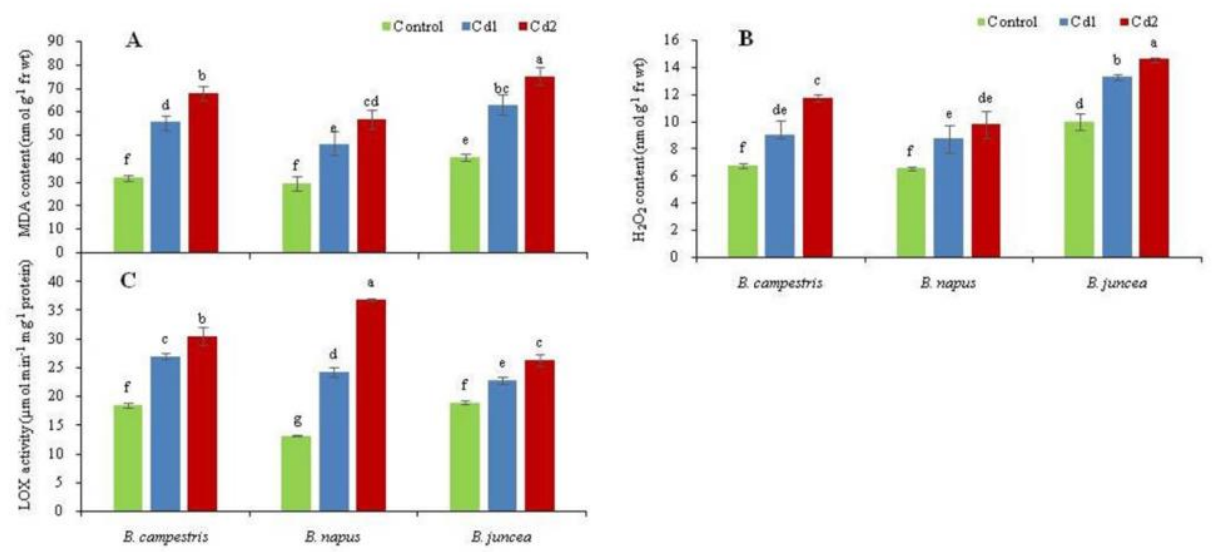

Fig 2. MDA content (A), $\mathrm{H}_{2} \mathrm{O}_{2}$ level (B), and LOX activity (C) of different Brassica species under Cd stress. Cd1 and Cd2 indicate $0.25 \mathrm{mM} \mathrm{CdCl}_{2}$ and $0.5 \mathrm{mM} \mathrm{CdCl}_{2}$, respectively. Means $( \pm \mathrm{SD})$ were calculated from three replications for each treatment. Bars with different letters are significantly different at $\mathrm{P} \leq 0.05$ applying Fisher's LSD test. 

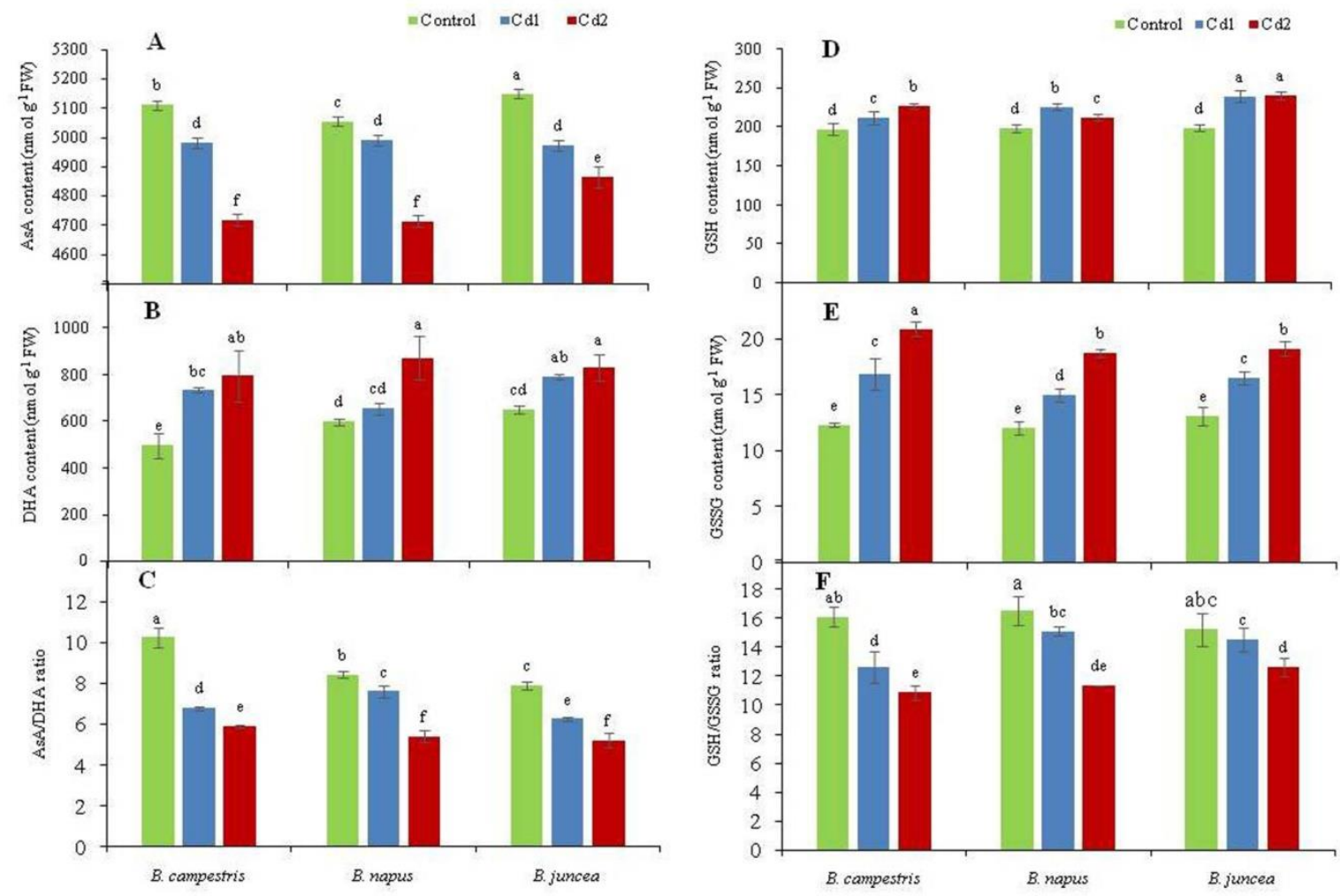

Fig 3. AsA content (A), DHA content (B), AsA/DHA ratio (C), GSH content (D), GSSG content (E), and GSH/GSSG ratio (F) of different Brassica species under Cd stress. Cd1 and $\mathrm{Cd} 2$ indicate $0.25 \mathrm{mM} \mathrm{CdCl}_{2}$ and $0.5 \mathrm{mM} \mathrm{CdCl}$, respectively. Means ( \pm SD) were calculated from three replications for each treatment. Bars with different letters are significantly different at $\mathrm{P} \leq 0.05$ applying Fisher's LSD test.
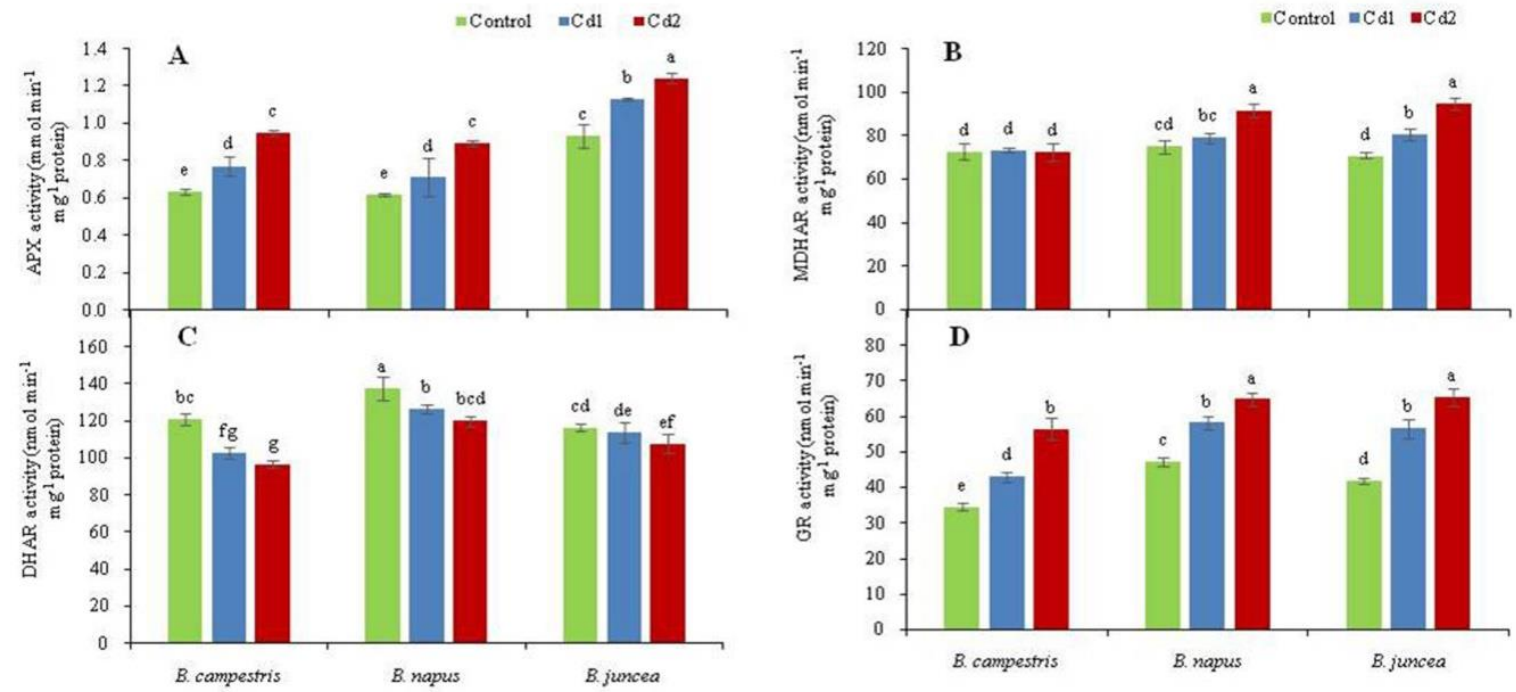

Fig 4. APX (A), MDHAR (B), DHAR (C), and GR (D) activities of different Brassica species under Cd stress. Cd1 and Cd2 indicate $0.25 \mathrm{mM} \mathrm{CdCl}_{2}$ and $0.5 \mathrm{mM} \mathrm{CdCl}_{2}$, respectively. Means $( \pm \mathrm{SD})$ were calculated from three replications for each treatment. Bars with different letters are significantly different at $\mathrm{P} \leq 0.05$ applying Fisher's LSD test. 

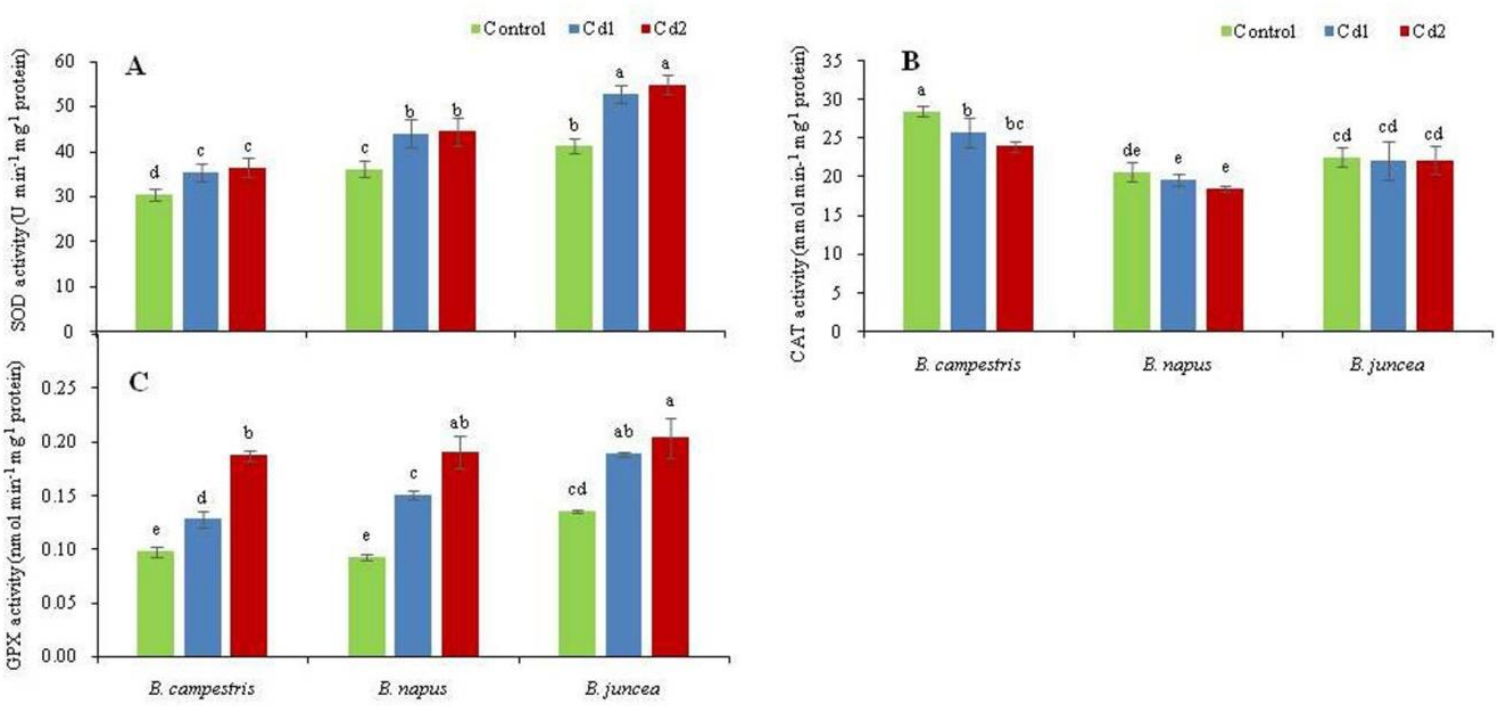

Fig 5. SOD (A), CAT (B), and GPX (C) activities of different Brassica species under Cd stress. Cd1 and Cd2 indicate $0.25 \mathrm{mM}$ $\mathrm{CdCl}_{2}$ and $0.5 \mathrm{mM} \mathrm{CdCl}_{2}$, respectively. Means $( \pm \mathrm{SD})$ were calculated from three replications for each treatment. Bars with different letters are significantly different at $\mathrm{P} \leq 0.05$ applying Fisher's LSD test.
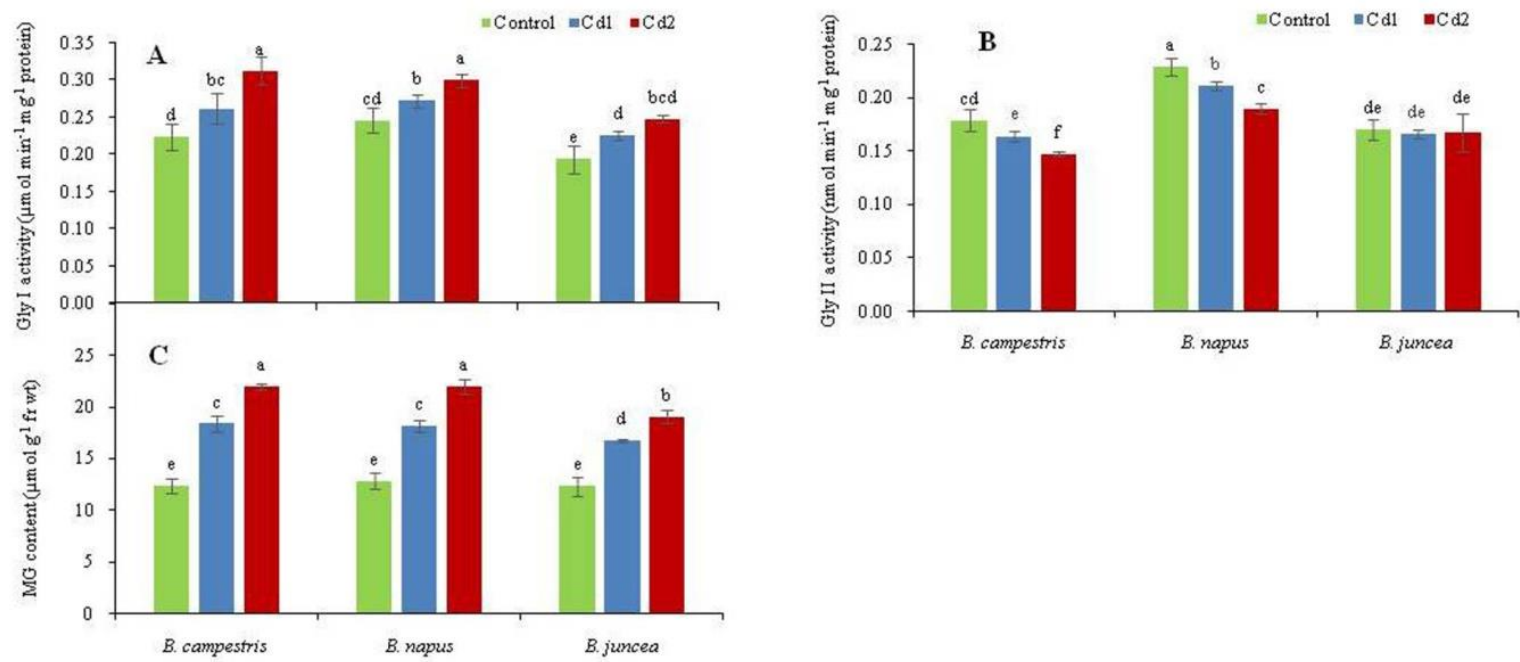

Fig 6. Gly I (A) activity, Gly II (B) activity, and MG content (C) of different Brassica species under Cd stress. Means ( \pm SD) were calculated from three replications for each treatment. Bars with different letters are significantly different at $\mathrm{P} \leq 0.05$ applying Fisher's LSD test.

in B. napus under 0.25 and $0.5 \mathrm{mM}$ Cd stress, respectively, whereas in B. juncea, it decreased by only 5 and $17 \%$, respectively (Fig 3F).

\section{Antioxidant enzymes}

Ascorbate peroxidase and GR activities of all the tested Brassica seedlings increased significantly under both levels of Cd stress compared with control (Figure 4A, D). Under 0.5 $\mathrm{mM} \mathrm{Cd}$, the increase in APX activity was lower in B. juncea. Treatment with $\mathrm{Cd}$ had no effect on the MDHAR activities of the $B$. campestris seedlings, but increased MDHAR was recorded for B. napus and B. juncea under both levels of $\mathrm{Cd}$ treatment (Figure 4B). Both treatments of Cd stress resulted in a significant decrease in DHAR activities in B. campestris and $B$. napus in contrast with the control seedlings, but in $B$. juncea, a significant decrease was observed only under 0.5 $\mathrm{mM} \mathrm{Cd}$ stress (Figure 4C). The activities of GPX and SOD increased significantly in all three Brassica species after $\mathrm{Cd}$ treatment. The increase in SOD was higher in $B$. juncea than the other two species (Figure 5A, B). Cadmium stress resulted in a decrease in CAT activities in B. campestris, whereas in B. napus and B. juncea, no significant difference was observed compared with the control seedlings (Figure $5 \mathrm{C})$.

\section{Glyoxalase system and methylglyoxal level}

The activity of Gly I increased in all three Brassica species compared with the control seedlings, whereas Gly II activity decreased in B. campestris and B. napus under both $\mathrm{Cd}$ doses, but no significant difference was observed in $B$. juncea (Figure 6A, B). A substantial increase in MG was observed under both levels of $\mathrm{Cd}$ stress compared with the control seedlings, but MG accumulation was lower in $B$. juncea compared with the other species (Figure 6C). 


\section{Discussion}

Brassica species are known as hyperaccumulators of heavy metal (Prasad and Freitas, 2003), but their metal accumulation capacities are not the same. According to Nouairi et al. $(2006 ; 2009)$, B. juncea possesses a greater potential for $\mathrm{Cd}$ accumulation than $B$. napus. They reported that levels of non-protein thiols and phytochelatins increased greatly in leaves of $B$. juncea by increasing Cd supply, but no change was observed in B. napus. Plants grown in heavy metal-contaminated medium showed higher metal accumulation in the roots than the shoots (Srivastava et al., 2014; Ahmad et al., 2015; Nahar et al., 2016; Rahman et al., 2016). In our present study, $\mathrm{Cd}$ exposure resulted in the accumulation of $\mathrm{Cd}$ in the root and shoot tissues of all three Brassica seedlings, with the highest accumulation showing in B. juncea. The root tissues accumulated higher $\mathrm{Cd}$ content than the shoot tissues of all three Brassica species.

Cadmium stress reduces the growth, development, and productivity of plants by disrupting different physiological processes (Sanita di Toppi and Gabbrielli, 1999), which were reflected in the findings of our study. In the present study, FW and DW of all three Brassica species decreased under Cd stress in a dose-dependent manner. On the other hand, plant height decreased significantly under $0.5 \mathrm{mM} \mathrm{CdCl}_{2}$ stress in B. campestris and B. napus, whereas no significant difference was observed in B. juncea. Therefore, in terms of growth, $B$. campestris was more sensitive to $\mathrm{Cd}$ stress. Growth reduction in response to $\mathrm{Cd}$ stress has also been reported for mustard (Iqbal et al., 2010), mung bean (Nahar et al., 2016), rice (Rahman et al., 2016), and for various Brassica species after exposure to excess $\mathrm{Zn}$ or $\mathrm{Cu}$ (Ebbs and Kochian, 1997).

Different abiotic stresses reduce leaf RWC and increase Pro content in wheat (Hasanuzzaman and Fujita, 2013), mung bean (Nahar et al., 2016) and rice (Rahman et al., 2016). Toxic metals increase accumulation of Pro and hamper plant water balance (Ahmad et al., 2015). Free Pro in plants acts as an osmoprotectant, metal chelator, and antioxidant. Therefore, Pro protects plants from free radical damage and improves phytochelatin synthesis by maintaining a favorable cellular environment and $\mathrm{Cd}$ sequestration (Gill and Tuteja, 2010). Accordingly, for identifying the tolerance level of plants under any stress, leaf RWC and Pro content are very important factors. In our study, leaf RWC decreased and Pro content increased in all three Brassica seedlings with the increase in stress level, but the decrease in leaf RWC was lower and the increase in Pro content was higher in B. juncea, suggesting that $B$. juncea is more tolerant to $\mathrm{Cd}$ stress than the other two species.

Chlorophyll content decreases as a result of inhibition of protochlorophyllide reduction and aminolevulinic acid synthesis (Stobart et al., 1985). Cadmium stress adversely affect photosynthesis by altering the photosystem II (Baszynski, 1986), decreasing amount of plastoquinone in the chloroplast (Krupa et al., 1992) and disrupting the calvin cycle (Weigel, 1985). In the present study, a significant reduction in the content of $\operatorname{chl} a$ and $\operatorname{chl} b$ was noticed in the leaves of all three Brassica species, but the rate of reduction was lower in B. juncea. A similar result was obtained by Nouairi et al., (2006), in which the total chl content reduction of $B$. juncea was significantly lower than B. napus.

Abiotic stresses at the molecular level accelerate the production of ROS such as ${ }^{1} \mathrm{O}_{2}, \mathrm{O}_{2}{ }^{-{ }^{-}}, \mathrm{H}_{2} \mathrm{O}_{2}$, and $\mathrm{OH}^{*}$ (Hasanuzzaman et al., 2012a). In our study, excessive production of $\mathrm{H}_{2} \mathrm{O}_{2}$ and $\mathrm{O}_{2}{ }^{--}$was recorded under different doses of $\mathrm{Cd}$ in all the tested Brassica species. Cadmium toxicity resulted in the production of ROS, which in turn converted fatty acids to toxic lipid peroxides, and caused membrane damage in cadmium-sensitive plants (Nouairi et al., 2009). In contrast to B. campestris and B. napus, an increased rate of MDA production was lower in the leaves of $B$. juncea (compared with its control) under both $\mathrm{Cd}$ treatments despite its high cadmium accumulation. Similar results were previously reported in different species of Brassica (Nouairi et al., 2006; 2009). The lower rate of MDA production in $B$. juncea seedlings seems to be closely related to heavy-metal tolerance in plants (Howlett and Avery, 1997). Therefore, these results clarify that all three Brassica plants have different defense strategies against $\mathrm{Cd}$ stress as well as oxidative stress. Lipoxygenase, an iron-containing enzyme responsible for membrane degradation (Macri et al., 1994), is an indicator of oxidative damage (Ali et al., 2005). Singh and Shah,(2014) reported that Cd causes oxidative damage in rice plants by increasing LOX activity. In our study, LOX activity increased with an increasing concentration of $\mathrm{Cd}$ in all three Brassica species, but compared with control, the rate of increase was lower in B. juncea. Higher LOX activity under $\mathrm{Cd}$ stress is supported by a higher level of MDA (Rahman et al., 2016). As in our study, the rate of increasing lipid peroxidation (MDA) resulting from $\mathrm{Cd}$ stress was lower in $B$. juncea, which was partly due to lower LOX activity in the same species, making the plant more tolerant than $B$. campestris and B. napus.

To scavenge ROS, plants possess a well-organized, efficient non-enzymatic (AsA, GSH, $\alpha$-tocopherol, phenolic compounds, alkaloids, and non-protein amino acids) and enzymatic (SOD, CAT, APX, GR, MDHAR, DHAR, GPX, POX, etc.) antioxidative defense system (Gill and Tuteja, 2010; Mittler et al., 2004). To maintain cellular redox potential for abiotic stress tolerance, the components of the AsA-GSH cycle perform a significant role (Foyer and Halliwell, 1976; Pang and Wang, 2008; Mahmood et al., 2010; Pang and Wang, 2010; Anjum et al., 2011). Ascorbate is a vital water-soluble antioxidant that reacts with different ROS including $\mathrm{H}_{2} \mathrm{O}_{2}, \mathrm{O}_{2}{ }^{--}$, and ${ }^{1} \mathrm{O}_{2}$. It can also scavenge $\mathrm{OH}^{\cdot}$ at diffusion-controlled rates (Smirnoff, 2005). Changes in AsA, DHA, and the AsA/DHA ratio are part of the antioxidant defense mechanism of plants (Alam et al., 2013). In our present study, the change in AsA and DHA contents was not same in all three Brassica species under both levels of Cd stress. Under the $0.5 \mathrm{mM}$ dose of $\mathrm{Cd}$, the rate of reduction of AsA, the AsA/DHA ratio, and the increasing rate of DHA was lower in $B$. juncea than $B$. campestris and $B$. napus, because the increase in APX activity was lower in $B$. juncea, which might render the species more able to scavenge ROS than the other species under Cd stress. Glutathione is often considered an important intracellular antioxidant of the AsA-GSH cycle, and the GSH/GSSG ratio in particular has a vital function in the redox status and stress signaling processes. Therefore, higher GSH/GSSG is considered to support improved abiotic stress tolerance including toxic metal stress (Gill and Tuteja, 2010; Hasanuzzaman et al., 2012a). Cd stress significantly increased the GSH levels in all three Brassica species, compared with the control seedlings, and the highest increase was observed in $B$. juncea. GSSG content also increased in all three species, much like GSH, with an increasing dose of $\mathrm{Cd}$, but the lowest rate of increase was recorded in $B$. juncea. That is why the lowest reduction in the GSH/GSSG ratio was recorded in B. juncea under Cd stress. An increased level of GSSG may be due to the oxidation of GSH to GSSG during the scavenging process of ROS (Nahar et al., 2016). Toxic metals increase GSH content, which scavenges ROS with the help of GPX and GST (Hasanuzzaman et al., 2012a; Szalai et al., 2009). In the 
present study, GPX increased significantly compared with the control plants in all the Brassica species tested.

In plant cells, SOD constitutes the frontline defense against ROS and it catalyzes and converts $\mathrm{O}_{2}{ }^{--}$to $\mathrm{H}_{2} \mathrm{O}_{2}$ (Hasanuzzaman et al., 2012a). Previous research findings showed that Cd stress increases SOD activity (Nahar et al., 2016; Rahman et al., 2016). In our study, SOD activity increased significantly in all three Brassica species after Cd treatment, but the rate of increase in SOD activity was higher in $B$. juncea than the other two species, which shows that $B$. juncea has a greater capacity to prevent ROS. Catalase converts $\mathrm{H}_{2} \mathrm{O}_{2}$ to $\mathrm{H}_{2} \mathrm{O}$ and $\mathrm{O}_{2}$, which contributes to preventing oxidative damage (Sánchez-Casas and Klesseg, 1994), but in our study, Cd stress resulted in a decrease in CAT activities in B. campestris, whereas in B. napus and $B$. juncea, no significant difference was observed compared with the control seedlings.

The four enzymes (APX, MDHAR, DHAR, and GR) of the AsA-GSH cycle work with AsA, GSH, and NADPH and together detoxify $\mathrm{H}_{2} \mathrm{O}_{2}$ in a series of cyclic reactions and again regenerate AsA and GSH (Hasanuzzaman et al., 2012b). Ascorbate peroxidase catalyzes the reduction of $\mathrm{H}_{2} \mathrm{O}_{2}$ to $\mathrm{H}_{2} \mathrm{O}$ by using AsA (Wang et al., 2006; Xu et al., 2008). On the other hand, GR regenerates AsA and GSH to maintain cellular balance with the help of MDHAR and DHAR (Mishra et al., 2013). Our present study revealed that the APX and GR activities of all the tested Brassica seedlings increased significantly under both levels of $\mathrm{Cd}$ stress compared with control, and the increase in APX activity was lower in B. juncea under higher Cd levels. Cd treatment had no effect on MDHAR activity in the $B$. campestris seedlings, but increased MDHAR was recorded for B. napus and $B$. juncea under both levels of $\mathrm{Cd}$ treatment. A significant decrease in DHAR activities was recorded in B. campestris and $B$. napus in contrast with the control seedlings, but in $B$. juncea a significant decrease was observed under only 0.5 $\mathrm{mM}$ Cd stress, which corroborate with GSH content of $B$. juncea because under mild stress GSH content increased rate was significantly higher than the other two species. With the GSH-GSSG pool, B. juncea showed higher upregulation of antioxidative enzymes. Similar findings were observed in $\mathrm{Cd}$ treated rice plants (Rahman et al., 2016).

The MG level markedly increases in different plants under abiotic stress including Cd stress (Hasanuzzaman et al., 2012c; Suhartono et al., 2014; Nahar et al., 2016; Rahman et al., 2016), which is similar to the findings of our present study. Upregulation of the MG detoxification system or glyoxalase system is very important for plants to improve stress tolerance against toxic MG or MG-induced oxidative stress (Yadav et al., 2005a). The enzymes of the glyoxalase system, Gly I and Gly II, can detoxify MG effectively in a two-step reaction. In the first step, MG is converted to SLG by using the Gly I enzyme, where GSH acts as co-factor, and in the second step, SLG is converted to D-lactate by using the Gly II enzyme, where GSH is recycled back (Yadav et al 2005b; Mustafiz et al., 2010). In the present study, Gly I activity increased in all three Brassica species, whereas Gly II activity decreased in B. campestris and B. napus under both 0.25 and $0.5 \mathrm{mM} \mathrm{Cd}$ doses, but no significant difference was observed in B. juncea. The increase in Gly I activity and the decrease in Gly II activity were also observed in mung bean (Nahar et al., 2016) and rice (Rahman et al., 2016) under $\mathrm{Cd}$ stress. Compared with the control seedlings, a marked increase in MG was observed in all three species of Brassica under both levels of Cd stress, but the increase in MG production was lower in B. juncea than the other two species. Lower MG levels in B. juncea are supported by the higher efficiency of its glyoxalase system.

\section{Materials and methods}

\section{Plant materials and stress treatments}

Uniform sized seeds of three Brassica species (Brassica campestris L. cv. BARI Sharisha 9, Brassica napus L. cv. BARI Sharisha 13 and Brassica juncea L. cv. BARI Sharisha 16) were selected and surface sterilized with $70 \%$ ethanol followed by washing several times with sterile distilled water. Then sterilized seeds were sown in perti dishes $(9 \mathrm{~cm})$ lined with six layers of filter paper moistened with $10 \mathrm{ml}$ of distilled water for germination and kept for 2 days in germinator. Each petri dish contained 60 germinated seedlings and those were grown under controlled conditions (light, $350 \mu$ mol photon $\mathrm{m}^{-1} \mathrm{~s}^{-2}$; temperature, $25 \pm 2^{\circ} \mathrm{C}$; relative humidity, 65-70\%) in growth chamber; 5,000-fold diluted Hyponex solution (Hyponex, Japan) was applied as nutrient every day according to necessity. Cadmium was added to the nutrient medium as $\mathrm{CdCl}_{2}$ in two concentrations: $0.25 \mathrm{mM}$ and $0.5 \mathrm{mM}$ on ten days old seedlings. Control seedlings were grown in Hyponex solution only. After three days of $\mathrm{Cd}$ treatment, leaves were harvested and used for studying various morphological and physiological parameters. The experiment was conducted following Completely Randomized Design (CRD) with nine treatments and it was repeated three times under the same condition.

\section{Measurement of growth parameters}

Plant height was taken from each treatment and expressed as $\mathrm{cm}$. Ten randomly selected fresh seedlings from each treatment were weighted, recorded and considered as fresh weight (FW). Dry weight (DW) was determined after drying the seedlings at $80^{\circ} \mathrm{C}$ in oven for $48 \mathrm{~h}$. Both DW and FW were expressed in milligram $(\mathrm{mg})$.

\section{Measurement of relative water content}

Relative water content (RWC) was measured according to Barrs and Weatherly (1962) using following formula: RWC $(\%)=[($ FW-DW $) /($ TW $-D W)] \times 100[$ Here TW means turgid weight]

\section{Measurement of Cd content}

Cadmium content was determined by using an atomic absorption spectrophotometer (Hitachi Z-5000, Japan). The plant samples were oven dried at $80^{\circ} \mathrm{C}$ for $72 \mathrm{~h}$. The dried samples from root and shoot $(0.1 \mathrm{~g})$ were ground and digested separately with acid mixture $\left(\mathrm{HNO}_{3}: \mathrm{HClO}_{4}=5: 1\right.$ $\mathrm{v} / \mathrm{v}$ ) for $48 \mathrm{~h}$ at $80^{\circ} \mathrm{C}$. Then absorbance of sample was recorded from atomic absorption spectrophotometer and $\mathrm{Cd}$ content of shoot and root was calculated using standard curve of known concentration.

\section{Measurement of chlorophyll content}

Chlorophyll (chl) content was measured following the method of Arnon (1949) after extraction of plant leaves by $80 \%$ $\mathrm{v} / \mathrm{v}$ acetone. 


\section{Measurement of proline content}

Proline (Pro) content was measured according to Bates et al. (1973) using acid ninhydrin.

\section{Histochemical detection of hydrogen peroxide and superoxide}

The hydrogen peroxide $\left(\mathrm{H}_{2} \mathrm{O}_{2}\right)$ and superoxide $\left(\mathrm{O}_{2}{ }^{-}\right)$were localized histochemically by staining of Brassica leaves according to the method described in Chen et al. (2010) with slight modification. Leaves were stained in $0.1 \% \quad 3$ diaminobenzidine (DAB) and $0.1 \%$ nitrobluetetrazolium chloride (NBT) solution for $24 \mathrm{~h}$ under dark condition for $\mathrm{H}_{2} \mathrm{O}_{2}$ and $\mathrm{O}_{2}{ }^{-}$, respectively. Incubated leaves were then immersed in boiling ethanol solution for blenching. After that brown spots was appeared due to the reaction of $\mathrm{DAB}$ with $\mathrm{H}_{2} \mathrm{O}_{2}$ and dark blue spots was appeared due to the reaction of NBT with $\mathrm{O}_{2}{ }^{-}$. Finally photographs were taken by placing the leaves on glass.

\section{Measurement of lipid peroxidation}

The level of lipid peroxidation was measured by estimating MDA content according Heath and packer (1968) with slight modifications (Hasanuzzaman et al., 2012b). The leaf samples $(0.5 \mathrm{~g})$ were homogenized in $3 \mathrm{ml} 5 \%(\mathrm{w} / \mathrm{v})$ trichloroacetic acid (TCA) and the homogenate was centrifuged at $11,500 \times g$ for $15 \mathrm{~min}$. One $\mathrm{ml}$ supernatant was mixed with $4 \mathrm{ml}$ of thiobarbituric acid (TBA) reagent $(0.5 \%$ of TBA in 20\% TCA). The reaction mixture was heated at $95^{\circ} \mathrm{C}$ for $30 \mathrm{~min}$ in a water bath and then quickly cooled in an ice bath and centrifuged again at $11,500 \times \mathrm{g}$ for $10 \mathrm{~min}$. The absorbance of the colored supernatant was measured at 532 $\mathrm{nm}$ and was corrected for non-specific absorbance at $600 \mathrm{~nm}$. The content of MDA was calculated by using the extinction coefficient of $155 \mathrm{mM}^{-1} \mathrm{~cm}^{-1}$ and expressed as nmol of MDA $\mathrm{g}^{-1} \mathrm{FW}$.

\section{Determination of hydrogen peroxide content}

Hydrogen peroxide was determined according to the method of Yu et al. (2003) using $0.1 \% \mathrm{TiCl}_{4}$ in $20 \% \mathrm{H}_{2} \mathrm{SO}_{4}(\mathrm{v} / \mathrm{v})$.

\section{Measurement of methylglyoxal level}

Methylglyoxal was measured following the method of Wild et al. (2012) using sodium dihydrogen phosphate and Nacetyl- L-cysteine.

\section{Extraction and measurement of ascorbate and glutathione}

Fresh leaves $(0.5 \mathrm{~g})$ were homogenized in $3 \mathrm{ml}$ ice-cold $5 \%$ meta-phosphoric acid containing $1 \mathrm{mM}$ Ethylenediaminetetraacetic acid (EDTA) using mortar and pestle. Homogenates were centrifuged at $11,500 \times \mathrm{g}$ for $12 \mathrm{~min}$ at $4^{\circ} \mathrm{C}$, and the supernatant was collected for analysis of AsA and GSH. Ascorbate content was determined following the method of Hunag et al. (2005) with some modifications. The supernatant was neutralized with $0.5 \mathrm{M} \mathrm{K}$-Pbuffer ( $\mathrm{pH}$ 7.0) and the oxidized fraction were reduced by $0.1 \mathrm{M}$ dithiothretitol. Total and reduced AsA was assayed spectrophotometrically at $265 \mathrm{~nm}$ in $100 \mathrm{mM} \mathrm{K}-\mathrm{P}$ buffer $(\mathrm{pH}$ 7.0) with 0.5 unit of ascorbate oxidase (AO). A specific standard curve with AsA was used for quantification. Oxidized AsA (DHA) was calculated by subtracting AsA from total AsA. The GSH pool was assayed according to previously described methods (Yu et al., 2003) with modifications as described by Paradiso et al. (2008). Aliquots $(0.2 \mathrm{~mL})$ of supernatant were neutralized with $0.3 \mathrm{ml}$ of 0.5 M K-phosphate buffer (pH 7.0). Based on enzymatic recycling, GSH is oxidized by 5,5-dithio-bis (2-nitrobenzoic acid) (DTNB) and reduced by nicotinamide adenine dinucleotide phosphate (NADPH) in the presence of GR and GSH content was evaluated by the rate of absorption changes at $412 \mathrm{~nm}$ of 2-nitro-5-thiobenzoic acid (NTB) generated from the reduction of DTNB. Oxidized glutathione was determined after removal of GSH by 2-vinylpyridine derivatization. Standard curves with known concentrations of GSH and GSSG were used. The content of GSH was calculated by subtracting GSSG from total GSH.

\section{Determination of protein}

The protein concentration of each sample was determined according to Bradford, (1976) using BSA as a protein standard.

\section{Enzyme extraction and assays}

Leaf tissue $(0.5 \mathrm{~g})$ was homogenized in $1 \mathrm{ml}$ of $50 \mathrm{mM}$ icecold K-P buffer ( $\mathrm{pH} 7.0$ ) containing $100 \mathrm{mM} \mathrm{KCl}, 1 \mathrm{mM}$ AsA, $5 \mathrm{mM} \beta$-mercaptoethanol and $10 \%$ (w/v) glycerol using a pre-cooled mortar pestle. The homogenates were centrifuged at $11,500 \times \mathrm{g}$ for $10 \mathrm{~min}$ and the supernatants were used for determination of enzyme activity. $0-4^{\circ} \mathrm{C}$ temperature was maintained for performing all the activities.

Lipoxygenase (EC 1.13.11.12) activity was determined following the method of Doderer et al. (1992) by monitoring the increase in absorbance at $234 \mathrm{~nm}$ using linoleic acid as a substrate. Superoxide dismutase (EC 1.15.1.1) activity was measured based on xanthine-xanthine oxidase system following the method of El-Shabrawi et al. (2010). Catalase (EC: 1.11.1.6) and GR (EC: 1.6.4.2) activities were assayed following the method of Hasanuzzaman et al. (2012b) by monitoring the decrease of absorbance at 240 and $340 \mathrm{~nm}$, respectively. Ascorbate peroxidase (EC: 1.11.1.11) and DHAR (EC: 1.8.5.1) activities were determined according to the method of Nakano and Asada (1981). Assay mixture for APX contained $50 \mathrm{mM}$ K-P buffer ( $\mathrm{pH} 7.0$ ), $0.5 \mathrm{mM}$ AsA, $0.1 \mathrm{mM} \mathrm{H}_{2} \mathrm{O}_{2}$ and $0.1 \mathrm{mM}$ EDTA. Reaction buffer of DHAR contained $50 \mathrm{mM}$ K-P buffer ( $\mathrm{pH}$ 7.0), $2.5 \mathrm{mM}$ GSH, 0.1 $\mathrm{mM}$ EDTA and $0.1 \mathrm{mM}$ DHA. Monodehydroascorbate reductase (EC: 1.6.5.4) activity was measured following the method as described in Hossain et al. (1984). The reaction mixture of MDHAR contained $50 \mathrm{mM}$ Tris- $\mathrm{HCl}$ buffer $(\mathrm{pH}$ 7.5), $0.2 \mathrm{mM}$ NADPH, $2.5 \mathrm{mM}$ AsA and 0.5 unit of AO. Glutathione peroxidase (EC: 1.11 .1 .9 ) activity was assayed by the method of Elia et al. (2003). The reaction mixture consisted of $100 \mathrm{mM}$ K-P buffer (pH 7.0), 1 mM EDTA, 1 $\mathrm{mM}$ sodium azide $\left(\mathrm{NaN}_{3}\right), 0.12 \mathrm{mM} \mathrm{NADPH}, 2 \mathrm{mM}$ GSH, 1 unit GR and $0.6 \mathrm{mM} \mathrm{H}_{2} \mathrm{O}_{2}$ (as a substrate). Glyoxalase I (EC: 4.4.1.5) activity was determined following the method of Hasanuzzaman et al. (2012b). Assay mixture of Gly I contained $100 \mathrm{mM} \quad \mathrm{K}-\mathrm{P}$ buffer $(\mathrm{pH}$ 7.0), $15 \quad \mathrm{mM}$ magnesiumsulphate, $1.7 \mathrm{mM}$ GSH and $3.5 \mathrm{mM}$ MG. Glyoxalase II (EC: 3.1.2.6) activity was determined according to Principato et al. (1987) with reaction mixture contained $100 \mathrm{mM}$ Tris-HCl buffer (pH 7.2), $0.2 \mathrm{mM}$ DTNB and $1 \mathrm{mM} S$-D-lactoylglutathione (SLG). 


\section{Statistical analysis}

The data were subjected to analysis of variance (ANOVA) and the mean differences were compared by a Duncan's multiple range test (DMRT) using XLSTAT v. 2015 software (Addinsoft, 2015) from three replicates. Differences at $P \leq 0.05$ were considered significant.

\section{Conclusion}

The results of our study show that Cd exposure to different Brassica species resulted in differences in Cd accumulation, growth, oxidative damage, and antioxidant defense. Growth suppression due to $\mathrm{Cd}$ accumulation was observed in all three Brassica species with increasing $\mathrm{Cd}$ concentration in the growth medium, but no significant decrease in plant height was observed in $B$. juncea even though it had the highest level of $\mathrm{Cd}$ of the tested species. Proline content, lipid peroxidation, ROS production, MG accumulation, and chl degradation increased with the increasing dose of $\mathrm{Cd}$, whereas leaf RWC decreased in all three tested species. The level of lipid peroxidation, ROS production, MG accumulation, chl degradation, and leaf RWC reduction were lower and the increase in Pro content was higher in B. juncea. Better performance of the antioxidant and methyl glyoxalase systems under both levels of $\mathrm{Cd}$ stress was observed in $B$. juncea compared with the other tested species even though it accumulated the highest level of $\mathrm{Cd}$ in its roots and shoots. Considering $\mathrm{Cd}$ accumulation capacity and physiological attributes, we conclude that of the studied Brassica species, $B$. juncea is a relatively tolerant species to Cd toxicity.

\section{Acknowledgments}

This research was funded by the Ministry of Education, Culture, Sports, Science and Technology (MEXT), Japan. We thank Mr. Dennis Murphy, United Graduate School of Agricultural Sciences, Ehime University, Japan, for a critical review and editing the English of the manuscript.

\section{References}

Addinsoft (2015) XLSTAT v. 2015: data analysis and statistics software for Microsoft Excel. Addinsoft, Paris, France.

Ahmad P, Sarwat M, Bhat NA, Wani MR, Kazi AG, Tran LP (2015) Alleviation of cadmium toxicity in Brassica juncea L. (Czern. \& Coss.) by calcium application involves various physiological and biochemical strategies. PLoS ONE. 10:e0114571.

Alam MM, Hasanuzzaman M, Nahar K, Fujita M (2013) Exogenous salicylic acid ameliorates short-term drought stress in mustard (Brassica juncea L.) seedlings by upregulating the antioxidant defense and glyoxalase system. Aust J Crop Sci. 7:1053-1063.

Ali MB, Hahn EJ, Paek KY (2005) Effects of temperature on oxidative stress defense systems: lipid peroxidation and lipoxygenase activity in Phalaenopsis. Plant Physiol Biochem. 43:213-223.

Anjum NA, Umar S, Iqbal M, Khan NA (2011) Cadmium causes oxidative stress in mungbean by affecting the antioxidant enzyme system and ascorbate-glutathione cycle metabolism. Russ J Plant Physiol. 58:92-99.

Arnon DT (1949) Copper enzymes in isolated chloroplasts polyphenal oxidase in Beta vulgaris. Plant Physiol. 24:1-15.
Barrs HD, Weatherley PE (1962) A re-examination of the relative turgidity technique for estimating water deficits in leaves. Aust J Biol Sci. 15:413-428.

Baszynski T (1986) Interference of $\mathrm{Cd}^{2+}$ in functioning of the photosynthetic apparatus in higher plants. Acta Soc Bot Poland. 55:291-304.

Bates LS, Waldren RP, Teari D (1973) Rapid determination of free proline for water stress studies. Plant Soil. 39:205207.

Bradford M (1976) A rapid and sensitive method for the quantitation of microgram quantities of protein utilizing the principle of protein-dye binding. Anal Biochem. 72:248254.

Chen F, Wang F, Wu F, Mao W, Zhang G, Zhou M (2010) Modulation of exogenous glutathione in antioxidant defense system against $\mathrm{Cd}$ stress in the two barley genotypes differing in $\mathrm{Cd}$ tolerance. Plant Physiol Biochem. 48:663-672.

Doderer A, Kokkelink I, van der Veen S, Valk B, Schram A, Douma A (1992) Purification and characterization of two lipoxygenase isoenzymes from germinating barley. Biochim Biophys Acta. 112:97-104.

Dong J, Wu FB, Zhang GP (2006) Influence of cadmium on antioxidant capacity and four microelement concentrations in tomato (Lycopersicon esculentum). Chemosphere. 64:1659-1666.

Dubey RS (2011) Metal toxicity, oxidative stress and antioxidative defense system in plants. In: Gupta SD (ed) Reactive oxygen species and antioxidants in higher plants. CRC Press, Boca Raton.

Ebbs SD, Kochian LV (1997) Toxicity of zinc and copper to Brassica species: implications for phytoremediation. J Environ Qual. 26:776-781.

Elia AC, Galarini R, Taticchi MI, Dorr AJM, Mantilacci L (2003) Antioxidant responses and bioaccumulation in Ictalurus melas under mercury exposure. Ecotoxicol Environ Safe. 55:162-167.

El-Shabrawi H, Kumar B, Kaul T, Reddy MK, Singla-Pareek SL, Sopory SK (2010) Redox homeostasis, antioxidant defense, and methylglyoxal detoxification as markers for salt tolerance in Pokkali rice. Protoplasma. 245:85-96.

Foyer CH, Halliwell B (1976) The presence of glutathione and glutathione reductase in chloroplasts: a proposed role in ascorbic acid metabolism. Planta. 133:21-25.

Gill SS, Khan NA, Anjum NA, Tuteja N (2011) Amelioration of cadmium stress in crop plants by nutrients management: morphological, physiological and biochemical aspects. Plant Stress. 5:1-23.

Gill SS, Tuteja N (2010) Reactive oxygen species and antioxidant machinery in abiotic stress tolerance in crop plants. Plant Physiol Biochem. 48:909-930.

Gratão PL, Polle A, Lea PJ, Azevedo RA (2005) Making the life of heavy metal stressed plants a little easier. Funct Plant Biol. 32:481-494.

Hall JL (2002) Cellular mechanisms for heavy metal detoxification and tolerance. J Exp Bot. 53:1-11.

Hasanuzzaman M, Fujita M (2012) Heavy metals in the environment: current status, toxic effects on plants and possible phytoremediation. In: Anjum NA, Pereira MA, Ahmad I, Duarte AC, Umar S, Khan NA (eds) Phytotechnologies: Remediation of Environmental Contaminants. CRC Press, Boca Raton.

Hasanuzzaman M, Fujita M (2013) Exogenous sodium nitroprusside alleviates arsenic-induced oxidative stress in wheat (Triticum aestivum L.) by enhancing antioxidant defense and glyoxalase system. Ecotoxicology. 22:584-596. 
Hasanuzzaman M, Hossain MA, Fujita M (2012c) Exogenous selenium pretreatment protects rapeseed seedlings from cadmium-induced oxidative stress by upregulating antioxidant defense and methylglyoxal detoxification systems. Biol Trace Elem Res. 149:248-261.

Hasanuzzaman M, Hossain MA, Teixeira da Silva JA, Fujita M (2012a) Plant responses and tolerance to abiotic oxidative stress: antioxidant defense is a key factor. In: Bandi V, Shanker AK, Shanker C, Mandapaka M (eds) Crop stress and its management: perspectives and strategies. Springer, Berlin.

Hasanuzzaman M, Nahar K, Alam MM, Fujita M (2012b) Exogenous nitric oxide alleviates high temperature induced oxidative stress in wheat (Triticum aestivum L.) seedlings by modulating the antioxidant defense and glyoxalase system. Aust J Crop Sci. 6:1314-1323.

Hasanuzzaman, Nahar K, Alam MM, Fujita M (2013) Adverse Effects of cadmium on plants and possible mitigation of cadmium-induced phytotoxicity. In: Hasanuzzaman $M$, Fujita $M$ (eds) Cadmium: Characteristics, Sources of Exposure, Health and Environmental Effects. Nova Science Publishers, New York, USA.

Heath RL, Packer L (1968) Photoperoxidation in isolated chloroplast: I. Kinetics and stoichiometry of fatty acid peroxidation. Arch Biochem Biophys. 125:189-198.

Heyes RB (1997) The carcinogenicity of metals in humans, Cancer Causes Control. 8:371-385.

Hossain MA, Nakano Y, Asada K (1984) Monodehydroascorbate reductase in spinach chloroplasts and its participation in the regeneration of ascorbate for scavenging hydrogen peroxide. Plant Cell Physiol. 25:385395.

Howlett NG, Avery SV (1997) Induction of lipid peroxidation during heavy metal stress in Saccharomyces cerevisiae and influence of plasma membrane fatty acid unsaturation. Appl Environ Microbiol. 63:2971-2976.

Huang C, He W, Guo J, Chang X, Su P, Zhang L (2005) Increased sensitivity to salt stress in ascorbate deficient Arabidopsis mutant. J Exp Bot. 56:3041-3049.

Iqbal N, Masood A, Nazar R, Syeed S, Khan NA (2010) Photosynthesis, growth and antioxidant Metabolism in Mustard (Brassica juncea L.) cultivars differing in cadmium tolerance. Agric Sci China. 9:519-527.

Krupa Z, Öquist G, Huner NPA (1992) The influence of cadmium on primary photosystem II photochemistry in bean as revealed by chlorophyll a fluorescence-a preliminary study. Acta Physiol Plant. 14:71-76.

Li L, He Z, Pandey GK, Tsuchiya T, Luan S (2002) Functional cloning and characterization of a plant efflux carrier for multidrug and heavy metal detoxification. J Biol Chem. 277:5360-5368.

Macri F, Braidot B, Petrusa E, Vianello A (1994) Lipoxygenase activity associated to isolated soybean plasma membranes. Biochim Biophys Acta. 1215:109-114.

Mahmood Q, Ahmad R, Kwak SS, Rashid A, Anjum NA (2010) Ascorbate and glutathione: protectors of plants in oxidative stress. In: Anjum NA, Chan MT, Umar S (eds) Ascorbate glutathione pathway and stress tolerance in plants. Springer, Dordrecht, Netherlands.

Mishra P, Bhoomika K, Dubey RS (2013) Differential responses of antioxidative defense system to prolonged salinity stress in salt tolerant and salt-sensitive Indica rice (Oryza sativa L.) seedlings. Protoplasma. 250:3-19.

Mittler R, Vanderauwera S, Gollery M, Van Breusegem F (2004) Reactive oxygen gene network of plants. Trends Plant Sci. 9:490-498.
Mustafiz A, Sahoo KK, Singla-Pareek SL, Sopory SK (2010) Metabolic engineering of glyoxalase pathway for enhancing stress tolerance in plants. Methods Mol Biol. 639:95-118.

Nahar K, Hasanuzzaman M, Alam MM, Rahman A, Suzuki T, Fujita M (2016) Polyamine and nitric oxide crosstalk: Antagonistic effects on cadmium toxicity in mung bean plants through upregulating the metal detoxification, antioxidant defense and methylglyoxal detoxification system. Ecotoxicol Environ Safe. 126:245-255.

Nakano Y, Asada K (1981) Hydrogen peroxide is scavenged by ascorbate-specific peroxidase in spinach chloroplasts. Plant Cell Physiol. 22:867-880.

Nouairi I, Ammar WB, Youssef NB, Miled DDB, Ghorbal MH, Zarrouk M (2009) Antioxidant defense system in leaves of Indian mustard (Brassica juncea) and rape (Brassica napus) under cadmium stress. Acta Physiol Plant. 31:237-247.

Nouairi I, Ben Ammar W, Ben Youssef N, Douja Daoud BM, Ghorbel MH, Zarrouk M (2006) Comparative study of cadmium effects on membrane lipid composition of Brassica juncea and Brassica napus leaves. Plant Science. 170:511-519.

Pang CH, Wang BS (2008) Oxidative stress and salt tolerance in plants. In: Lüttge U, Beyschlag W, Murata J (eds) Progress in botany. Springer, Heidelberg.

Pang CH, Wang BS (2010) Role of ascorbate peroxidase and glutathione reductase in ascorbate-glutathione cycle and stress tolerance in plants. In: Anjum NA, Chan MT, Umar $\mathrm{S}$ (eds) Ascorbate-glutathione pathway and stress tolerance in plants. Springer, Dordrecht.

Paradiso A, Berardino R, de Pinto M, di Toppi L, Storelli S, de Gara FT (2008) Increase in ascorbate-glutathione metabolism as local and precocious systemic responses induced by cadmium in durum wheat plants. Plant Cell Physiol. 49:362-374.

Prasad MNV, Freitas HMO (2003) Metal hyperaccumilation in plants- Biodiversity prospecting for phytoremediation technology. Electron J Biotechnol. 6:285-321.

Principato GB, Rosi G, Talesa V, Govannini E, Uolila L (1987) Purification and characterization of two forms of glyoxalase II from rat liver and brain of Wistar rats. Biochem Biophys Acta. 911:349-355.

Qadir S, Qureshi MI, Javed S, Abdin MZ (2004) Genotypic variation in phytoremediation potential of Brassica juncea cultivars exposed to Cd stress. Plant Sci. 167:1171-1181.

Rahman A, Mostofa MG, Nahar K, Hasanuzzaman M, Fujita M (2016) Exogenous calcium alleviates cadmium-induced oxidative stress in rice seedlings by regulating the antioxidant defense and glyoxalase systems. Braz J Bot. 39:393-407.

Robinson BH, Banuelos G, Conesa HM, Evangelon WH, Schulin R (2009) The phytomanagement of trace elements in soil. Crit Rev Plant Sci. 28:240-260.

Sánchez-Casas P, Klesseg DF (1994) A salicylic acid-binding activity and a salicylic acid-inhibitable catalase activity are present in a variety of plant species. Plant Physiol. 106:1675-1679.

Sanita di Toppi L, Gabbrielli R (1995) Response to cadmium in higher plants. Environ Exp Bot. 41:105-130.

Sharma P, Dubey RS (2007) Involvement of oxidative stress and role of antioxidative defense system in growing rice exposed to toxic levels of aluminium. Plant Cell Rep. 26:2027-2038.

Singh I, Shah K (2014) Exogenous application of methyl jasmonate lowers the effect of cadmium-induced oxidative injury in rice. Phytochemistry. 108:57-66. 
Smirnoff N (2005) Ascorbate, tocopherol and carotenoids: Metabolism, pathway engineering and functions. In: Smrinoff N (ed) Antioxidants and Reactive Oxygen Species in Plants. Blackwell Publishing, Oxford, UK.

Srivastava RK, Pandey P, Rajpoot R, Rani A, Gautam A, Dubey RS (2014) Exogenous application of calcium and silica alleviates cadmium toxicity by suppressing oxidative damage in rice. Protoplasma. 252:959-975.

Srivastava S, Tripathi RD, Dwivedi UN (2004) Synthesis of phytochelatins and modulation of antioxidants in response to cadmium stress in Cuscuta reflexa - an angiospermic parasite. J Plant Physiol. 161:665-674.

Stobart AK, Griffiths WT, Ameen-Bukhar RPI, Sherwood (1985) The effect of $\mathrm{Cd}^{2+}$ on the biosynthesis of chlorophyll in leaves of barley. Physiol Plant. 63:293-298.

Suhartono E, Triawanti, Leksono AS, Djati MS (2014) The role of cadmium in proteins glycation by glucose: Formation of methylglyoxal and hydrogen per-oxide in vitro. J Med Bioeng. 3:59-62.

Szalai G, Kellos T, Galiba G, Kocsy G (2009) Glutathione as an antioxidant and regulatory molecule in plants under abiotic stress conditions. Plant Growth Regul. 28:66-80.

Wang Y, Wisniewski M, Meilan R, Cui M, Fuchigami L (2006) Transgenic tomato (Lycopersicon esculentum) overexpressing CAPX exhibits enhanced tolerance to UV-B and heat stress. J Appl Hortic. 8:87-90.
Weigel HJ (1985) Inhibition of photosynthetic reactions of isolated intact chloroplast by cadmium. J Plant Physiol. 119:179-189.

Wild R, Ooi L, Srikanth V, Münch G (2012) A quick: convenient and economical method for the reliable determination of methylglyoxal in millimolar concentrations: the N-acetyl-L-cysteine assay. Anal Bioanal Chem. 403:2577-2581.

Xu WF, Shi WM, Ueda A, Takabe T (2008) Mechanisms of salt tolerance in transgenic Arabidopsis thaliana carrying a peroxisomal ascorbate peroxidase gene from barley. Pedosphere. 18:486-495.

Yadav SK, Singla-Pareek SL, Ray M, Reddy MK, Sopory SK (2005b) Transgenic tobacco plants overexpressing glyoxalase enzymes resist an increase in methylglyoxal and maintain higher reduced glutathione levels under salinity stress. FEBS Lett. 579:6265-6271.

Yadav SK, Singla-Pareek SL, Reddy MK, Sopory SK (2005a) Methylglyoxal detoxification by glyoxalase system: a survival strategy during environmental stresses. Physiol Mol Biol Plants. 11:1-11.

Yadav SK, Singla-Pareek SL, Sopory SK (2008) An overview on the role of methylglyoxal and glyoxalases in plants. Drug Metabol Drug Interact. 23:51-68.

Yu CW, Murphy TM, Lin CH (2003) Hydrogen peroxideinduces chilling tolerance in mung beans mediated through ABA-independent glutathione accumulation. Funct Plant Biol. 30:955-963. 